\title{
“EL OTRO” AL TELÉFONO. RELATOS DESDE LA PANDEMIA CAUSADA POR EL COVID 2019
}

\author{
Rafaela Díaz Villalobos \\ Psicóloga Clínica. U. Extremadura \\ rdiaz@unex.es
}

Recepción Artículo: 27 octubre 2021 Admisión Evaluación: 27 octubre 2021 Informe Evaluador 1: 28 octubre 2021 Informe Evaluador 2: 29 octubre 2021 Aprobación Publicación: 30 octubre 2021

\section{RESUMEN}

Con motivo de la Pandemia causada por el Covid 2019, se produjeron unos acontecimientos sociales que tuvieron honda influencia en nuestra estructura psíquica individual y organizativa como grupos humanos de convivencia.

Recordamos las prohibiciones de contactos con otras personas que no fueran familiares convivientes; las exigencias de lavados y desinfección; los temores y la incertidumbre ante ese virus desconocido que causaba graves dolencias en individuos sanos. Muertes. Abrumados por la saturación de hospitales, de tanatorios, la falta de medios, las miradas de angustia, Ios sonidos de ambulancias y ejército desinfectando, por el desconocimiento de lo que estaba sucediendo, cada persona trató de recomponer su vida cotidiana y sus rutinas para mantener el ritmo vital a unos niveles aceptables (bio-psico-sociales).

En Cáceres se organizaron en torno al Ayuntamiento de la ciudad, grupos de voluntarios coordinados por Jóvenes del Consejo de la Juventud y distintos colectivos que fueron posteriormente ejerciendo los liderazgos. La organización en barrios, en comunidades de vecinos, en torno a pequeñas tiendas de proximidad, en parroquias, fue impresionante. El grupo al que me refiero tomó el nombre de RED-COR y llegó a tener en torno a 2.000 voluntarios. No hay ni una sola empresa en la ciudad que agrupe a tantos trabajadores.

El 24 de Marzo de 2020 respondieron a mi ofrecimiento. Se generó un Grupo de Asesoramiento Psicológico de Psicólogos Expertos, 11 en total y 12 con un coordinador, que en ese momento preparaba su Tesis doctoral en Derecho. Sin salir de casa, puesto que por edad era sujeto de riesgo, respondimos a la demanda ciudadana desde nuestra formación. Por teléfono.

Palabras clave: pandemia; covid-19; RED-COR; incertidumbre; temor; bio-psico-social

\section{ABSTRACT}

"The other" on the phone. Stories from the pandemic caused by covid 2019. On the occasion of the Pandemic caused by Covid 2019, there were social events that had a deep influence on our individual and organizational psychic structure as human groups of coexistence. 


\section{“El OTRO” AL TELÉFONO. RELATOS DESDE LA PANDEMIA CAUSADA POR EL COVID 2019}

We recall the prohibitions on contacts with other people who were not family members; the demands of washing and disinfection; the fears and uncertainty of this unknown virus that caused serious ailments in healthy individuals. Deaths. Overwhelmed by the saturation of hospitals, mortuaries, the lack of means, the looks of anguish, the sounds of ambulances and the disinfecting army, due to the ignorance of what was happening, each person tried to rebuild their daily lives and their routines to maintain the vital rhythm to acceptable levels (bio-psychosocial).

In Cáceres, groups of volunteers coordinated by the Youth of the Youth Council and different groups that were later exerting leadership were organized around the City Council. The organization in neighborhoods, in neighboring communities, around small proximity stores, in parishes, was impressive. The group I am referring to took the name RED-COR and had around 2,000 volunteers. There is not a single company in the city that groups so many workers.

ON March 24, 2020 I had the first call in response to my offer. From there, a group of Psychological Advice of Expert Psychologists was created, 11 in total and 12 with the coordinator, who at that time was preparing his doctoral thesis in Law. Without leaving home, since he was subject to risk due to his age, we responded to the citizen demand from our formation. By phone.

Keywords: pandemic; covid-19; RED-COR; uncertainty; fear; bio-psycho-social

\section{PREÁMBULO}

Tras la puesta en marcha del Grupo de Atención y Asesoramiento Psicológico a finales de Marzo, se fijan una serie de criterios:

Acompañamiento/asesoramiento/apoyo a los Grupos de Voluntarios, en un grupo de Zoom abierto todos los lunes por la tarde.

Atención telefónica, por teléfono oculto, a personas derivadas para el Grupo de Psicología según cuadrante establecido

Se concretarían sesiones y duración profesionalmente según el caso.

Respuesta a peticiones en la página Web abierta. Derivaciones.

Solución, en la medida de lo posible, a demandas de particulares o institucionales en el teléfono general. Orientaciones.

El 11 de Junio de 2020, emitimos las Conclusiones del al Grupo de Coordinación General de Voluntarios del Ayuntamiento de Cáceres. (RED-COR):

Dejaría de funcionar como grupo operativo a finales de Julio.

Las nuevas peticiones se derivarían a los Servicios y Recursos de la Comunidad Extremeña.

El Grupo quedaba constituido y a disposición del Ayuntamiento.

\section{DESARROLLO}

En este documento se reflexiona, a modo de "Estudio de Casos", sobre algunas de las intervenciones realizadas.

\section{Intervención- 1. Estoy solita.}

Mujer de 80 años, vive sola. Varios hijos independientes, y nietos. Al retirarse el permiso para salir de casa y los contactos en el interior de la misma con no convivientes, esta señora se encuentra desconcertada, sobre todo con sentimientos de abandono - aunque nunca utilizó el término - porque nadie de la familia ha vuelto a entrar en su casa. Depende de una vecina de su planta que le trae la compra y habla con ella a través de la puerta. Cuando la organización de voluntarios comienza a atenderla, el voluntario asignado requiere atención psicológica para ella.

Tiene miedo de lo que pueda estar haciendo a lo largo del día y de la noche, escucha que vive sin horarios; le extrañan las quejas, el desorden de pensamiento y las disertaciones sobre la comida y la eliminación. Afirma 
que ninguno de sus hijos le llama, aunque él sabe que eso no es cierto. El chico le trae compra o medicinas, tira basura, habla con ella a través de la puerta, le razona acerca de lo que está sucediendo, las dificultades para los encuentros y visitas familiares y le indica soluciones a pequeños problemas domésticos que con la situación de restricción se convierten en grandes (teléfono, baterías, cambios de bombillas, resintonización de canales de Radio 0 TV, pilas en mandos, puertas que ahora suenan o se arrastran, etc.) Durante el día suele estar activa y puntual en las horas estipuladas para encargos, entregas o llamadas. En las noches relata actividades sin sentido. No sabemos si duerme.

- Esta era la situación común a muchas personas que vieron cortado el contacto con el exterior de manera brusca sin alcanzar a comprender bien el alcance- .

Está de acuerdo en recibir una llamada de una psicóloga, porque no le importa hablar con alguien por teléfono... Estoy solita. Acordamos días y hora de llamada. Se presenta de manera muy educada una señora que plantea confusiones y dudas. Verborreica. Parece ser alguien con mucha fortaleza y capacidad de organizar su vida - y las de los demás - Ahora no es capaz, ni lo percibe, de reorganizar su actividad, ni su pensamiento.

De la información y del contacto profesional, se deduce:

Recibe frecuentemente llamadas y alimentos cocinados de los hijos, dinero u otros asuntos resultados de gestiones que ella les pide. Lo niega.

Narra alteración de horarios y de ingestas que generan problemas gástricos para lo que señala actividades en absoluto favorables para solucionarlos.

Mantiene abierta la agenda con los nombres y los números de teléfono de los médicos para que le ofrezcan soluciones a lo que le está pasando. Llama frecuentemente, según dice. No obtiene respuesta.

Las deposiciones, que según ella eran inexistentes, constituían una preocupación para el voluntario, por las actividades que decía realizar para llevarlas a cabo. No le presto importancia a sus diarreas u obstrucciones, e intento organizar el área mental.

Está nutrida por la comida que le traen los hijos o la vecina. La revisión de las basuras por el voluntario indica que no tira comida; sí envases. Sigue comprando.

No sabemos el nivel de limpieza que hay en la casa, pero ella no parece preocuparse por ese tema. Habla de su autocuidado a niveles básicos y no se atasca con ideas de suciedad 0 asco.

Orientada, porque lo anota, según dice, recuerda el nombre, el día y la hora que llamará otra persona para hablar. No sabemos de qué grupo procede. Pero como a mí no me importa hablar, que me Ilame... Le cuento cosas, más o menos para entretenerla.

Percibo desde el principio la confianza. Y que a mí no quiere entretenerme admitiendo la confidencialidad. Acordamos dos charlas a la semana de 50 minutos por teléfono, para posteriormente poner una. El encuadre del caso señala una respuesta de negación, de refugio, ante la avalancha de sucesos difíciles de procesar y la situación de indefensión/dependencia, a la que no parece estar acostumbrada.

Partiendo del sencillo esquema de atención bio-psico-social, comenzamos a hablar de hábitos de alimentación, higiene y cuidado. Y de horarios. Cuando comienza a admitir las áreas de realidad que yo puedo señalar por la información del voluntario que le atiende, y por sus deslices en la narración, trabajamos reestructuración cognitiva que me calma, señora, dice.

\section{Esto no puede estar sucediendo da paso a Esto sucede.}

Admite que a veces exige a sus hijos que le traigan determinados alimentos de parafarmacia o complementos alimenticios que suponemos incluye en la dieta. Admite que le traen comida preparada. Admite que habla muchas veces con ellos. Progresivamente, la conversación es fluida. Disfrutamos ambas de la misma. Cuando he de señalarle algo importante, le digo: anótelo. Ella lo anota y lo guarda, según dice, en la caja de fotografías de su familia.

Al mes de haber establecido el contacto, me dice que la siguiente llamada coincide con su cumpleaños. 


\section{“El OTRO” AL TELÉFONO. RELATOS DESDE LA PANDEMIA CAUSADA POR EL COVID 2019}

Cuando llamo, le animo a cantar y cantamos juntas. Noto que hay alguien más en la habitación: Han venido a felicitarme mi hijo y mis nietos, pero no debemos decírselo a nadie.

Este día de su cumpleaños, fue un punto de inflexión importante para el cambio:

Pudo sentir alegría por su cumpleaños aún en momentos de drama y mostrar ésta ante un público familiar que se mantuvo en silencio.

Se alegró conmigo de cumplir años; lo presenciaron sus hijos y ella pudo reconocer que estaban allí. Van flexibilizándose las normas. De ahí a la peluquería hay un paso. Efectivamente lo da. Llama a su peluquera habitual y le atiende en casa.

En Junio programamos sesión de despedida. Escucho de nuevo que hay alguien en la casa. Es el voluntario que me va a poner unas cortinas.

Hablo con el chico. En esta alegría compartida de los tres, felicito al chico por la extraordinaria atención a la señora. El me habla de la caja de fotografías familiares y de la buena conversación. No nos hemos aburrido con ella, no.

Cuando se está detrás de una puerta, la vida que se lleva dentro es una incógnita. Pero los extraños también somos incógnitas. En aquella difícil situación, los tres extraños estuvimos bien.

\section{Intervención no 2. Yoga y Silencio.}

Llega la petición a través de una mujer que afirma que su hermana, en otro domicilio, tiene una Depresión que ella cree muy agravada, porque hubo de dejar todos los tratamientos médicos y asistenciales de rehabilitación por un Ictus acaecido meses atrás. Por su marido e hijo, sabe que no se levanta de la cama, negándose también a hablar con ella por teléfono. Informa que siempre fue depresiva.

De algún modo, hablan con ella y le sugieren la posibilidad de que alguien le ayude por teléfono. Lo admite. La articulación está sumamente alterada: encuentro dificultades para comprender el discurso. Equivocadamente lo asocié al posible tratamiento farmacológico para la depresión. Acordamos tener conversaciones de $1 / 2$ hora dos días a la semana.

Aún hoy, no sé si tenía 48, 58, 68 o 78 años. Su hijo era estudiante y con su marido no hablaba. Se agota por el esfuerzo en la comunicación y se enfada si no la comprendo. Quiero ayudarla. Lo entiende y responde a mis preguntas sobre la vida de ahora. De ellas derivo que está bien alimentada, limpia, atendida, y en una habitación en silencio de la que no sale. Siente rabia hacia los médicos que no responden a sus Ilamadas. Se han pospuesto todas sus citas. Hablamos de ello.

Manifestaba desinterés por todo, estar sin fuerzas, abatida. Deprimida. En la cuarta sesión, hablamos de la vida de antes, y ahí escuché "Yoga". ¿Usted hace yoga?, quizás pueda tirarse de la cama a la alfombra cada mañana y poner en práctica lo que sabe. Para mi sorpresa, comienza cada mañana a tirarse a la alfombra e ir aumentando el tiempo de estiramientos. Llega a relajarse. Anuncia: Es el mejor momento del día.

Siempre estuvo atenta a la hora fijada, para lo cual debía abandonar su habitación y sentarse en el salón del cual salían el hijo y el marido. Cuando le pregunto que a dónde se desplazan, no responde. En su discurso de articulación difícil, fui comprendiendo el impacto del Ictus y transcribo mejor sus palabras. Y sus silencios.

En esa rememoranza de la vida de antes, aparece un cuadro de amigas que tomaban el café cuando terminaban las sesiones de rehabilitación. Hablamos de ello.

Describe la calle como un lugar deseable. Hacemos ejercicios visuales frente a la ventana mirando el horizonte, describiendo el paisaje ciudadano. Añora las charlas con las amigas. Habla de la ropa que se pondrá cuando se reúnan.

Un día me pidió cambio de hora, pues su hijo iba a acompañarla a la peluquería. Otro día me informó que habían Ilamado del Centro de Rehabilitación para ver qué tal se encontraba y para decirle que pronto continuarían los tratamientos.

Me parece entender que está agradecida. Le pido permiso para informar a su hermana que fue quien pidió la atención psicológica. Está de acuerdo pero sobre la hermana también guarda silencio. 
Hablamos de progresos: Estoy mejor. No quiere interferir en la vida del hijo, muy buen hijo, que ha de estudiar para los exámenes, y por eso debo luchar, para ser más autónoma. Apoyo su evolución, y acordamos la sesión de despedida.

En ella, creo que estaban presentes su hijo y su marido. Había alguien más en la habitación. En mi imaginación: Más de una persona en el salón en penumbra. Respeté su silencio.

\section{Intervención 3. La Relajación.}

En la página web, un joven solicita atención para su padre: varón recientemente jubilado, funcionario. Convive con su esposa en un domicilio nuevo al que se trasladaron hace seis meses. Varios hijos y nietos. Existe comunicación telefónica, por video conferencia y tras la puerta.

Estamos muy preocupados con las obsesiones de mi padre por la limpieza y la angustia ante cualquier contacto con alguien que no sea mi madre. No nos permite que vayamos a verlos y no sale para nada a la calle. Nosotros les hacemos las compras. Cuando aún no se podía salir a la calle, el problema no fue percibido, pero ahora que las medidas de confinamiento se han relajado (Mayo 2020), hemos creído que es necesario ayudarle a salir de esos temores y ansiedades que manifiesta ante cualquier asunto, porque nunca ha sido así. Ha sido un hombre jovial, deportista, afable, con amigos, y partidario de reuniones familiares.

Puestos en contacto con el sujeto, se inicia la recogida de datos, explicitación del problema, y planificación del tratamiento telefónico. Las Ilamadas serán dos en días alternos en las dos primeras semanas; posteriormente, una llamada semanal. La duración de las mismas será de 50/60 minutos.

En el encuadre, se observa que han coincidido asuntos críticos en los últimos seis meses que le dificultan anclarse en esta nueva realidad:

- La jubilación.

- El cambio de domicilio y de vecindario;

- Las pérdidas de relaciones con compañeros de trabajo.

- La pérdida de actividad deportiva reglada con grupos.

El sujeto se describe como "normal", sorprendido por la respuesta que ha tenido a la situación de Pandemia. Sabe que necesita ayuda, que está incapacitado para vivir con normalidad. Está dispuesto a hacer lo que sea para recuperarse, pero no sabe cómo salir de este bucle obsesivo y ansioso.

Charlamos sobre su vida, su familia, sus intereses, sus amigos, sus costumbres. En el recorrido de su historia personal, no se observan antecedentes personales o familiares de interés. Narra su propia evolución desde la infancia hasta ahora, que es abuelo, con la impresión de haber hecho siempre lo que había que hacer, con honestidad y sinceridad, tomando como modelo las enseñanzas y las palabras - que suele repetir como refranes - de su padre que murió hace un par de años, y por el que parece haber llevado a cabo un duelo adecuado.

Es un hombre inteligente y práctico, que reconoce el valor de lo realizado, porque había que realizarlo. Utilizamos su propia historia como soporte, ahora que la incertidumbre y el temor a lo desconocido es el sentimiento personal dominante. Así, su propia narración se convierte en un elemento favorable, de orgullo por lo conseguido. La confianza en su familia para ayudarle en este trance es absoluta. Otro elemento favorable es que afirma dormir muy bien. Y otro, finalmente, que admite que como deportista que ha dejado de practicar, necesita retomar rutinas de movimiento, estiramientos y elasticidad para sustentar musculatura y encontrar un mínimo de bienestar. Está motivado para ello pero no ha dado el paso.

Reconoce una fobia obsesiva, a la enfermedad y al contagio. Esta reacción le ha inmovilizado en el domicilio del que no puede salir y en el miedo al contacto con cualquier cosa. Hablamos de alimentación, y de manera fortuita describe el sistema de limpieza y desinfección de cada pieza de fruta o verdura. Cocina él prácticamente con exclusividad. Informa que había perdido en torno a 15 kilos. Revisamos alimentación y trabajamos en la eliminación de miedos/fantasías sobre la elaboración de alimentos básicos como el pan o las carnes. Incluimos elementos en la dieta que fueran altamente nutritivos o calóricos y que le ofrecieran una absoluta seguridad, como por ejemplo los frutos secos con cáscara, la fruta de piel gruesa, legumbres con vaina, etc. 


\section{“El OTRO” AL TELÉFONO. RELATOS DESDE LA PANDEMIA CAUSADA POR EL COVID 2019}

Los últimos 25 minutos de la sesión, desde el principio, fueron dedicados a aprender técnica de relajación y comprender sus beneficios. Nos pareció adecuado mantener el espacio desde el que hablábamos como espacio de calma para, diariamente, trabajar en la extinción de la ansiedad practicando la tranquilización afectiva y compensando la tensión a que diariamente estaba sometido, a todos los niveles.

En la estructuración sencilla de aspectos biológicos psíquicos y sociales, el biológico fue tomando su lugar, y lentamente generaba bienestar en el sujeto, lo que le llevó a fidelizarse con la ingesta ordenada de nutrientes, según sus costumbres anteriores, y el ejercicio o los estiramientos dentro de la casa.

Diariamente practicaba la relajación según lo aprendido.

Por sugerencia de su esposa, comenzó a leer. Esto fue muy importante. Desarrolló un hábito que anteriormente no tenía, pero que utilizamos para afianzar el avance en las capacidades de comprensión, razonamiento, concentración y recuerdo. Avanzaba con facilidad en la lectura y también pudo seguir alguna noticia en la televisión sin retirarse por la ansiedad. Esto permitió unir su propia experiencia, de manera novedosa con la de otros y enriquecerse emocionalmente - para su sorpresa - en este diálogo. En alguna ocasión reconoció que si algo bueno le estaba dejando la pandemia, era ese descubrimiento de la lectura, de lugares y personajes desconocidos e interesantes. La pareja, gran lectora y comunicadora, le inició en la conversación de otras cosas ajenas a ellos y a la inseguridad. Temas de descanso.

La realización de tareas fuera de casa (compras, paseos, búsquedas de herramientas) que supusieran riesgo de encuentro con alguien ajeno, fue difícil. El contacto social, trabajado en visualización en la relajación, tardó en conseguirse. Pudo salir solo a practicar deporte; charlar con un amigo de ello por teléfono, pero mantenía el miedo al roce con el desconocido que podía encontrar por las escaleras de la casa, al salir a la calle o por los lugares donde practicaba el deporte. Dificultaba el objetivo, el proceso de lavado y desinfección de toda la ropa y calzado que había llevado y de él mismo.

La reunión con unos amigos, en casa de éstos, pudo realizarse al cabo de mes y medio de tratamiento. Posteriormente pudo recibir a sus hijos una hora en la casa. El temor a que le trajeran el virus, se mantuvo durante bastante tiempo.

Los avances en el área social fueron dándose lentamente, como había que darlos, admitiendo como compañera a la incertidumbre, diluyéndose el impacto en que era compañera social de todos. La repetición de las palabras incertidumbre, miedo, muerte, Covid 19, ansiedad, alegría, risa, tristeza, fantasía, calma, satisfacción., ayudó a normalizar los sentimientos.

Finalmente, una tarde de Julio, cuando ya sabíamos que terminaríamos en un par de sesiones de despedida y de revisión de lo conseguido, escuché niños en la casa. Audazmente, los hijos habían venido a visitarle con los nietos. Un acierto. Aún con temor, pudo beneficiarse de la alegría del encuentro.

En sujetos sanos, las decisiones familiares suelen erigirse como aciertos.

\section{Intervención 4. Poemas y Duelo.}

Una señora de más de 70 años vive con su hijo adulto y ha perdido a su hermana, enferma previamente, durante el periodo de pandemia. No puedo salir sola a la calle; antes salía con mi hermana, joven y alegre, paseábamos por la ciudad, hasta que cogió una enfermedad que la ha matado.

El joven trae las compras. No abandona la habitación, el comedor, mientras hablo con su madre. En una ocasión le señalé el hecho, indicándole que pudiera sugerir al joven que saliera... No se atreve. Tampoco escucho televisión o radio. No sé qué hace mientras estamos al teléfono. Con este encuadre, sumamente difícil porque no se propiciaba intimidad, acordamos las llamadas y el trabajo de ayuda para superar el duelo.

En el sencillo esquema bio-psico-social, animo a la señora, que, mientras hablamos se asome a la ventana y me describa lo que ve en el horizonte. Al principio no ve nada. Dice que le cuesta trabajo levantarse y sentarse porque está entumecida.

Seguimos ejercitando en cada sesión la visión en la distancia, y recordando los movimientos que hacía 
cuando iba al Centro de Mayores. De ahí comenzó a realizar en su habitación, todos los días según afirmaba, los estiramientos que había aprendido en las clases de gimnasia.

Se sentía bien con estas cosas, pero no quería olvidar la pérdida de la hermana. Es como si traicionara su recuerdo. En las conversaciones, cuando no está el hijo, van saliendo asuntos difíciles de la relación que no han de ser tratados ahora, y menos con el condicionante de la imprevisible presencia del hijo. Aparto. Es muy inteligente y percibe mi molestia por la presencia intermitente del hijo y la decisión de apartar.

La señora está sumamente agradecida por cómo va sintiéndose. Llora menos (siempre a escondidas del hijo). Duerme mejor y sin pesadillas. Confía en mí y me lee poesías que ha escrito. Descubro que es una gran lectora, creyente, y con facilidad para la escritura. A partir de ahí, aunque el hijo esté presente, ella lee párrafos que le han interesado 0 se anima a escribir poesías nuevas. Un día hablamos de la posibilidad de ofrecer o encargar misas por su hermana y poderlas ver por internet en las parroquias que las ofrecen. Lo admite, y aunque parece que el hijo no apoya la idea, dice que son tonterías mías, ella, a través de su teléfono móvil lo consigue. En sesiones posteriores me habla de la parroquia donde va a misa y reza por la hermana que murió.

Le animo a salir a tomar el sol durante 10 minutos a la calle. Ya ha visto que ve bien y que puede caminar. Ella sola va aumentando el tiempo. No logro saber si el hijo le acompaña. Cuando me habla de ir a la peluquería, le animo y felicito por la idea. Comprende que el duelo ha de pasarlo progresivamente. Le paso videos grabados en el grupo que pueden ayudarle. El primero lo vemos juntas. Hablamos de hacer una última sesión y le pido una poesía para que yo guarde.

La peluquería, en las señoras que yo he visto, ha sido el detonante de ponerse de nuevo en el mundo.

\section{REFERENCIAS BIBLIOGRÁFICAS}

AEN (2020). El COVID-19: El apoyo psicológico a los profesionales sanitarios, a la población general y a las personas con trastornos mentales. Campaña Estatal de la AEN "Desde casa te escucho". Asoc. Esp. Neuropsiq.I Profesionales de Salud Mental. Madrid.

https://ome-aen.org/guia-de-apoyo-psicosocial-durante-esta-epidemia-de-coronavirus/

Asociación por el Derecho a la Salud/Asociación de Salud Mental y Psiquiatría Comunitaria (2020): Guía de Intervención Psicosocial durante esta epidemia de coronavirus. Bilbao.

https://copib.es/intranet/files/26_03_2019_27_49Guia_Intervencion_Psicosocial__COVID_19_final_ y_figuras.pdf

Asociación por el Derecho a la Salud/Asociación de Salud Mental y Psiquiatría Comunitaria (2020): Guía de APOYO AL DUELO durante esta epidemia de coronavirus. Bilbao.

https://ome-aen.org/apoyo-al-duelo-durante-esta-epidemia-de-coronavirus/

Berger, P. L. y Luckmann, T. (1966): La construcción social de la realidad. Amorrortu.

Colegio Profesional De Psicología De Aragón: (Grupo de Intervención en Emergencias y Catástrofes (GIPEC)): ¿Cómo te hace sentir la covid? Recomendaciones para aprender a gestionar nuestras emociones en tiempos de pandemia. www.coppa.es. Zaragoza.

Ceberio M. Linares J L. (2005): Ser y hacer en terapia sistémica. Paidós.

Díaz Villalobos, R.: La deconstrucción psicológica. Periódico Extremadura. . https://www.elperiodicoextremadura.com/caceres-local/2020/07/13/deconstruccion-psicologica43861210.html

De la Torre Martí, M; Pablo Cebrián, R. (2018): Guía para la Intervención Telepsicológica. COP de Madrid. (PDF) https://www.copmadrid.org/web/publicaciones/guia-para-la-intervencion-telepsicologica

De van Grieken M. J. (2020): Covid-19: Acompañamiento psicoterapéutico remoto. Umbral de nuevas prácticas sistémicas. Psicología.com. 2020 VOL 24. - ISSN: 1137-8492. http://psiqu.com/1-10425

Grupo de Salud Mental para la intervención en la crisis por Covid19 (2020): Protocolo de Salud Mental para la intervención en la pandemia por coronavirus( Hospital Universitario la Paz, Hospital Universitario Príncipe de Asturias, Hospital Infantil Universitario Niño Jesús). Madrid, 15-3-2020. 


\section{“El OTRO” AL TELÉFONO. RELATOS DESDE LA PANDEMIA CAUSADA POR EL COVID 2019}

Moriconi V. Barbero J. (2020). Guía de Acompañamiento al Duelo. COVID-19. Colegio Oficial de Psicología de Madrid. Marzo 2020.

http://www.cop.es/uploads/PDF/GUIA-ACOMPANAMIENTO-DUEL0.pdf

Odriozola C (2020). Coronavirus y Duelo: 4 etapas y afrontar la situación de aislamiento.

Canal de Youtube: https://cutt.ly/Ver-en-el-canal-de-Carlos-Odriozola 28-3-2020

Pakman, M. (2011): Palabras que permanecen, palabras por venir: Micropolítica y poética en Psicoterapia. Gedisa.

Perea P. (2020). Duelo en tiempos del coronavirus. Despedir a un ser querido sin velatorio ni funeral. ¿Cómo hacerlo? Colegio Oficial de Psicólogos de Andalucía Oriental.

V.AA (Marzo 2020): Guía para el abordaje no presencial de las consecuencias psicológicas del brote epidémico del covid-19 en la población general -Universidad Complutense De Madrid. (PDF)

https://www.ucm.es/clinicadepsicologia/file/guia-covid-19-ucmprofesional 